\title{
Hundred and Eleven Cases of Subfascial Breast Augmentation in Trans Women-A Single-Center Experience
}

\author{
Sasanka Sekhar Chatterjee ${ }^{1,2}$ Manoj Khanna ${ }^{1}$ \\ ${ }^{1}$ Consultant, Enhance Aesthetic and Cosmetic Clinic, Kolkata, \\ West Bengal, India \\ 2Former Professor, Department of Plastic Surgery, Institute of Post \\ Graduate Medical Education and Research, Kolkata, West Bengal, India

\begin{abstract}
Address for correspondence Sasanka Sekhar Chatterjee, MS, MCh, DNB, PhD, Consultant, Enhance Aesthetic and Cosmetic Clinic, 12, UN Brahamchari Street, Kolkata 700017, West Bengal, India (e-mail: sschatterjee161@gmail.com).
\end{abstract}

\begin{abstract}
Keywords

- augmentation mammoplasty

- subfascial

- trans women

Hundred and eleven patients of breast augmentation in trans women operated between January 2004 and September 2019 are presented. Two surgeons conducted the study with a slightly different antibiotic regime. Only round implants were used. Till December 2017, 72 implants used were textured. Thereafter, we switched over smooth silicone gel implants more for reasons of availability than others. It was used in 39 patients. We did not notice any difference in results. Our postoperative regimes consisted of antibiotics (usually amoxicillin + clavulanic acid) for 10 days, restricted shoulder movements for 3 weeks, use of an inner brassiere and outer sports vest for 2 months. Routes of implantation were either periareolar or inframammary, former being selected as per choice of the patient, provided the hemicircumference of the areola was $4.5 \mathrm{~cm}$ or more. We never used transaxillary route. The implants were always placed in a subfascial pocket. Routine irrigation of the pocket with $5 \%$ povidone iodine was done before insertion of implant. From 3 weeks postoperatively, routine massage of breasts for a period of 6 to 8 weeks were advised. Complications included delayed minor wound healing problems usually in periareolar technique requiring secondary suture under local anesthesia. This was negligible with inframammary technique. Capsular contracture was found in 12 patients. Two of these merited intervention but one of them refused operation. In one patient, implant had to be extracted due to severe suppurative infection resulting from a separate incidence of traumatic injury with hematoma formation 2 weeks post operatively. Poor scarring including one keloid were noticed in 11 patients.
\end{abstract}

\section{Introduction}

Increasing demands for feminizing surgery are seen in trans women today. Of all feminizing procedures, breast augmentation is among the most commonly performed in this category $\mathrm{y}^{1,2}$ of patients as it results in immediate change in external appearance. It must be mentioned that these patients presenting to us are men with castrated genitals. There is always a demand for large breasts and an attractive cleavage irrespective of the physical stature, width of the chest, size of
DOI https://doi.org/

$10.1055 / \mathrm{s}-0040-1708227$

ISSN 0970-0358. nipple-areolar complex (NAC), interareolar distance, lack of adequate fat cushion, and tight skin envelope $e^{3,4}$ ( -Fig. 1).

\section{Materials and Methods}

Hundred and eleven patients of consecutive breast augmentation by silicone gel implants in trans women attending at a private clinic in Kolkata were included in this study. Our preoperative preparations included whole body bath with povidone iodine (7.5\%) surgical scrub solution on the day before 
and also on the day of operation. An oral dose of amoxycillin + clavulanic acid in the dose of $1.2 \mathrm{~g}$ or $625 \mathrm{mg}$ (as per individual preference of the two surgeons of the center-those who had $1.2 \mathrm{~g}$, continued a twice daily dose and the other in thrice daily dose postoperatively) was administered the night before and on the morning of operation.

\section{Preoperative Markings}

In standing position, markings were made at $6 \mathrm{~cm}$ on all sides centering on the nipple and another line $1 \mathrm{~cm}$ beyond

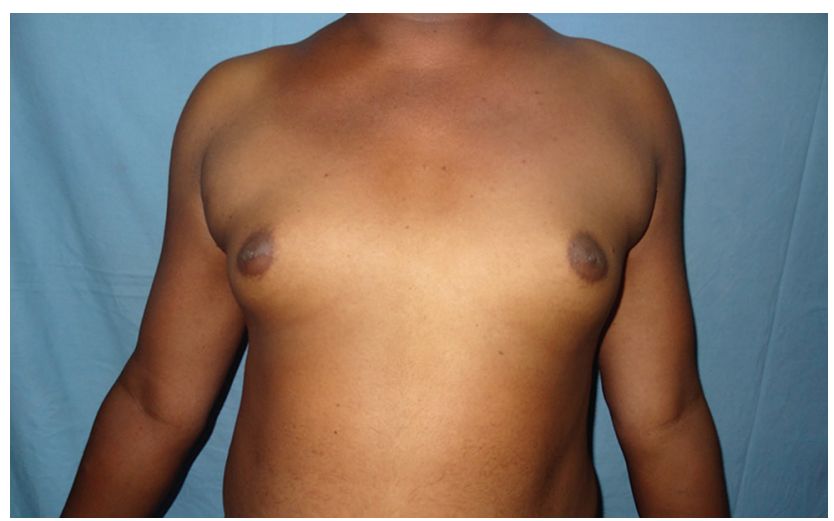

Fig. 1 Typical features of a trans woman - Broad shoulders \& sternum, wide inter NAC distance. Hormone treatment has resulted in a breast mound and medium sized NAC not sufficient for implant through periareolar incision.
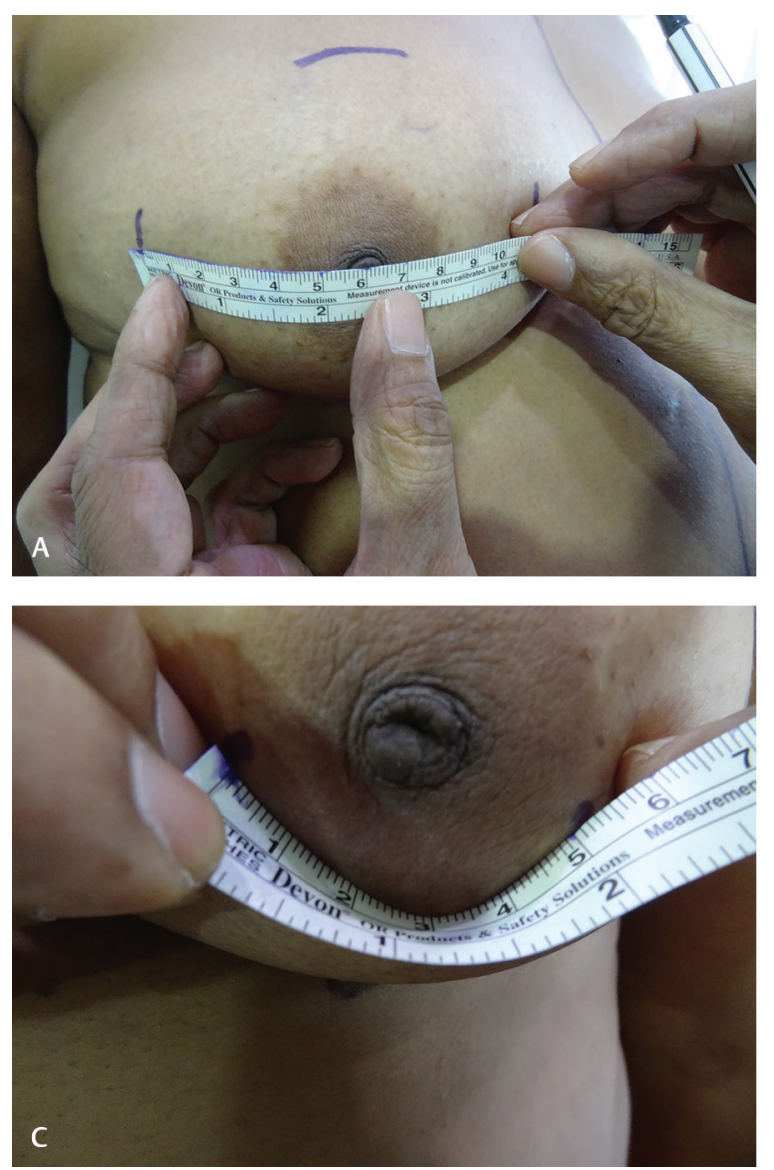

was drawn as a guide to restrict the dissection of the pocket beyond the markings. Periareolar and inframammary incisions are marked to the extent of $5 \mathrm{~cm}(\boldsymbol{- F i g}$. 2). The latter starts from a point falling vertically from the medial edge of NAC, 1 to $1.5 \mathrm{~cm}$ below the inframammary border, proceeding in a curvilinear manner laterally for $5 \mathrm{~cm}$ ( - Fig. 3). Implants we used so far had a base diameter ranging from 9.5 to $12.25 \mathrm{~cm}$, projection range being 4.5 to $6.1 \mathrm{~cm}$ and volume ranging between 180 and $550 \mathrm{~mL}$.

\section{Procedure}

The operation table is tilted $\sim 30^{\circ}$ toward the opposite side for operation on the right breast. Authors have used either periareolar (NAC hemicircumference at least 4.5, preferably $5 \mathrm{~cm}$ ) or inframmary (always $5 \mathrm{~cm}$ in length) incisions. Preference of the patient was taken into consideration only if their demand for larger implants corresponded with the adequacy of NAC size. After the skin incision, diathermy in coagulating mode was used for dissecting down to the pectoralis major muscle. fascia. Thereafter, same diathermy dissection continued subfascially ${ }^{5-7}$ all around till the lateral border of sternum medially and anterior axillary line laterally. Superior and inferior limits were reached according to the preoperative markings.

Inframammary incisions, somewhat curvilinear to conform to the breast shape are placed 7 to $7.5 \mathrm{~cm}$ below the nipple. Adjustments are made according to the tightness of skin envelope. Incision is deepened down to the fascia over
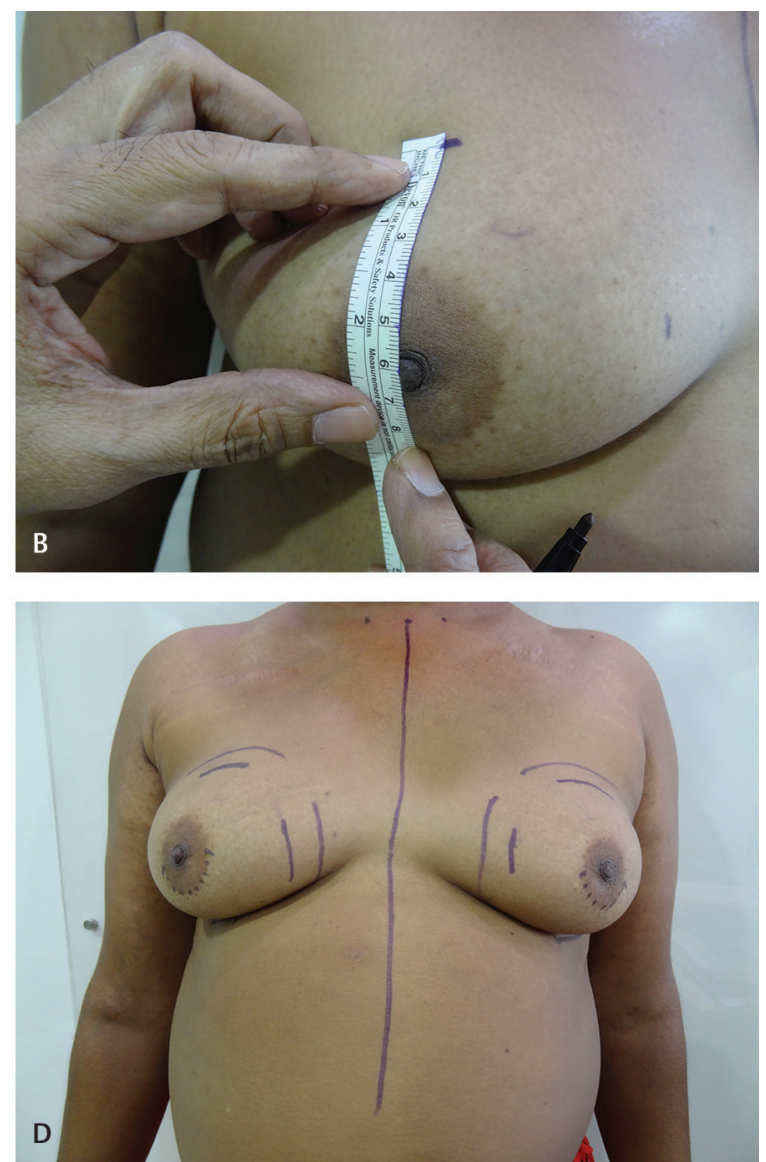

Fig. 2 Preoperative markings. (A) $6 \mathrm{~cm}$ marks medial and lateral to NAC. (B) $6 \mathrm{~cm}$ mark above the nipple. (C) Marking the periareolar $5 \mathrm{~cm}$ incision. (D) Markings completed, outer marks beyond $6 \mathrm{~cm}$ is to limit dissection. 

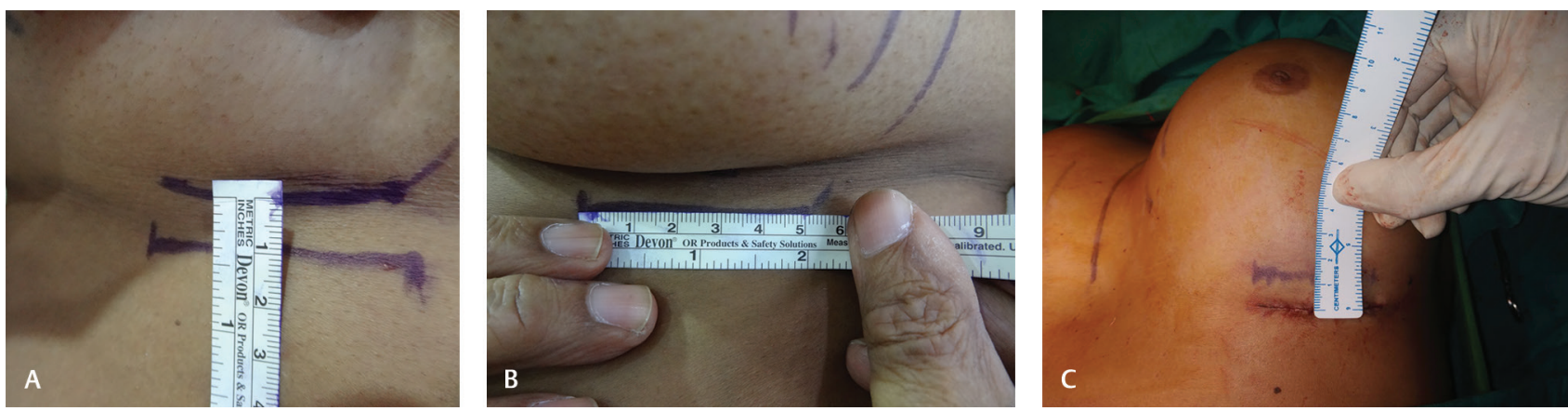

Fig. 3 Inframammary markings. (A) Marking of inframammary border. In this case, it was at $6 \mathrm{~cm}$ from the nipple. (B) Incision line $1 \mathrm{~cm}$ below the border. (C) Ultimate placement of scar (in another patient) in the new inframammary border, original mark is seen about $1.5 \mathrm{~cm}$ above.

the pectoralis major medially and followed over its lateral border laterally where the fascia blends with that of serratus anterior slips. Subfascial dissection proceeds with diathermy coagulation upwards ( - Fig. 4). Once the NAC is reached a finger dissection is attempted with sweeping movements to make some space (-Fig. 5). A lighted retractor is then inserted and rest of the dissection is completed with diathermy as described. The dissection is usually bloodless but in case one or two perforators bleed, they are coagulated separately. A narrow cuff of fascia is raised in the caudal edge of fascial incision to aid closure.

Mops are inserted in the pocket and dissection proceeds to the other side after tilting the table to around $30^{\circ}$ toward the surgeon. Surgeon may need to change side in case of inframammary incision. The size of the mops we use are $10 " \times 8.5$ " ( - Fig. 6) with thickness of 8 layers of gauze. A rough estimate can be made of the size of the implant to be inserted by the number of mops that can be tightly packed in the pocket. One mop of this size equals to roughly $100 \mathrm{~mL}$. Mops are taken out in the reverse order of their insertion, usually the right breast pocket is inspected first and after ensuring hemostasis, $\sim 10 \mathrm{~mL}$ of $5 \%$ povidone iodine solution is sprayed in the cavity and left as such when the same procedure is performed for the other side after tilting. At this point, the surgeon and assistant both change gloves, wash them with normal saline, and then smears the gloves with small amount of 5\% povidone iodine. A fresh drape is applied on the abdomen and lower chest of the patient. The cavities are reinspected and povidone iodine is wiped off. During insertion of implants, all movements in the theater are avoided as far as possible ( $\bullet$ Fig. 7). The wound is closed in four layers. First two layers are of 3'0' polypropylene, innermost layer is continuous and second layer is interrupted suture. If the incision is inframammary, care is taken to fixate the edges of closure to deeper layers ${ }^{8}$ to prevent migration of implant and ensure scar in the inframammary fold. Two layers of $3^{\prime} 0$ ' poliglecaprone (monocryl) are used for interrupted dermosubdermal and continuous subcuticular sutures. The patient is discharged after 2 hours or as soon as she feels fit to walk.

\section{Postoperative Regime}

Elastic adhesive figure of " 8 " strapping is done for the breasts. Patients are asked to restrict their shoulder

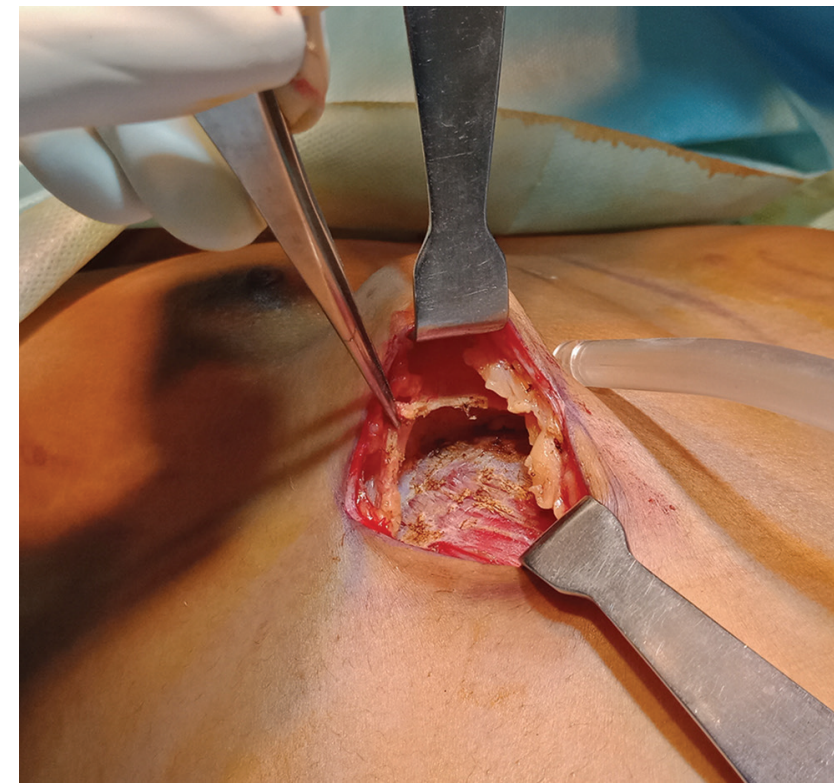

Fig. 4 Dissection via inframammary incision. The fascia is held in a dissecting forceps and for display skin and subcutaneous tissue is shown held by a retractor.

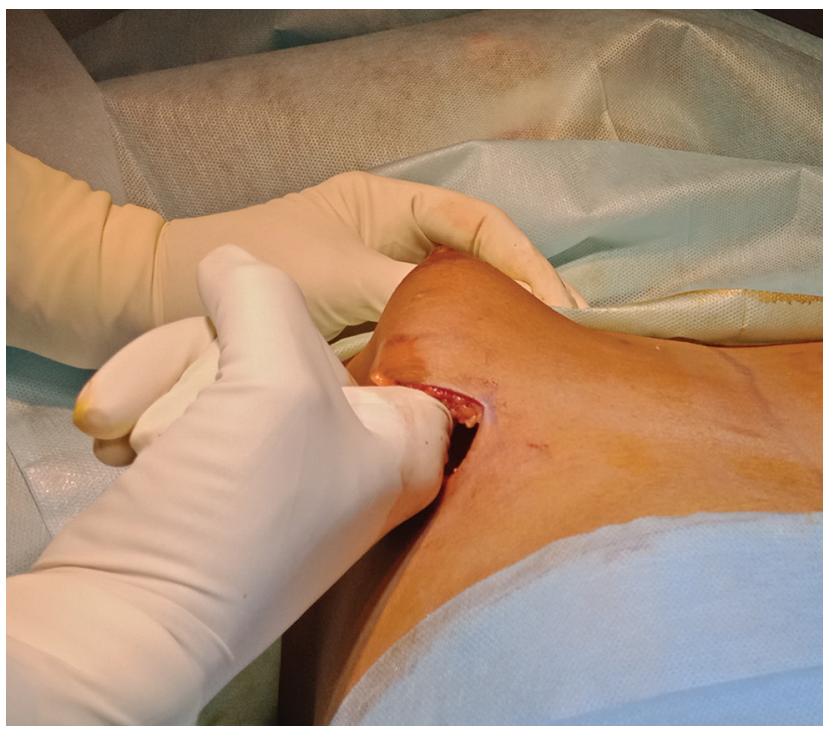

Fig. 5 The index finger inserted subfascially for blunt dissection in preparation for entry of a long bladed lighted retractor. 

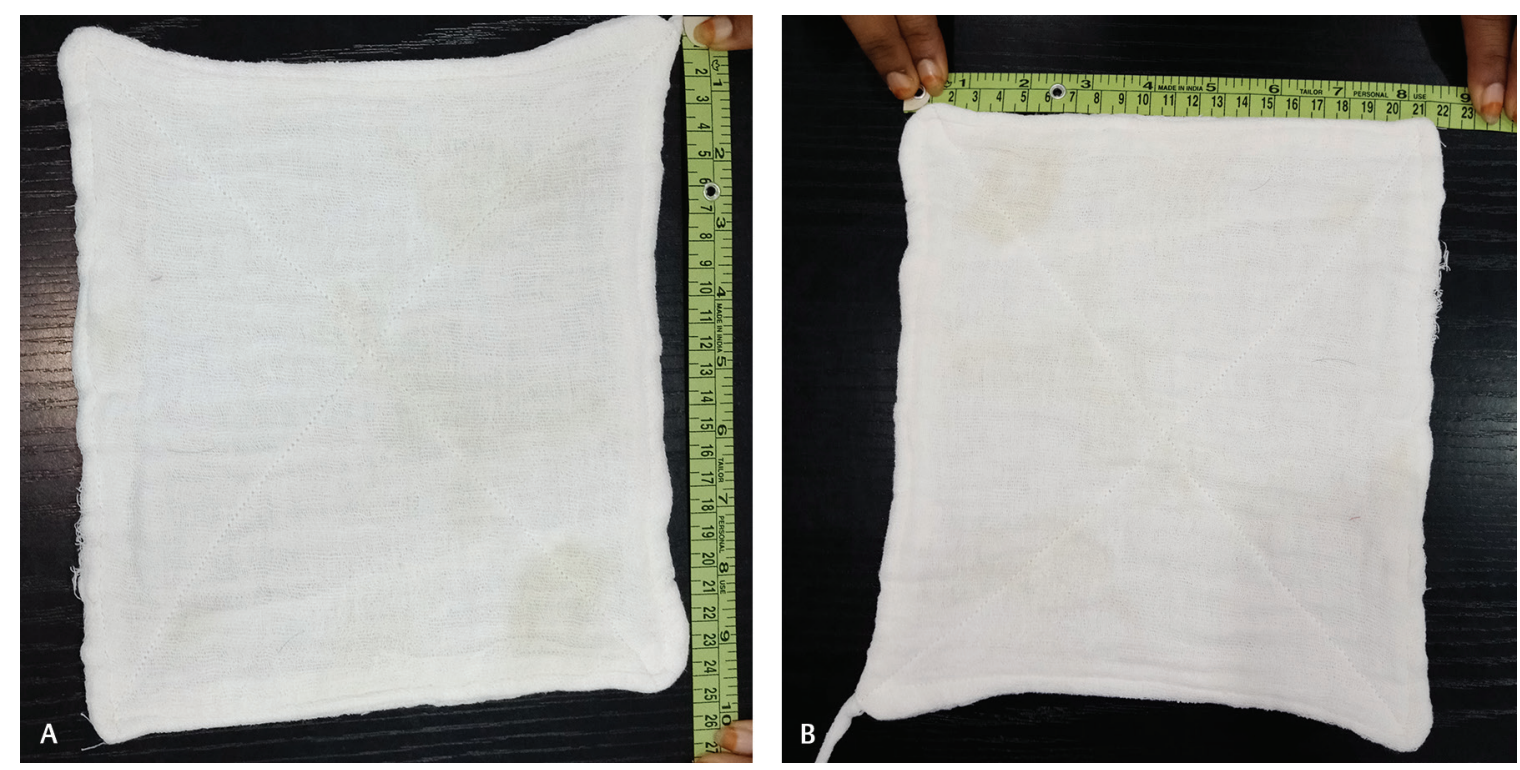

Fig. 6 Showing the measurements of the mops in use (A - length, B - width). These act as a fair guide in selecting the size of the implant.
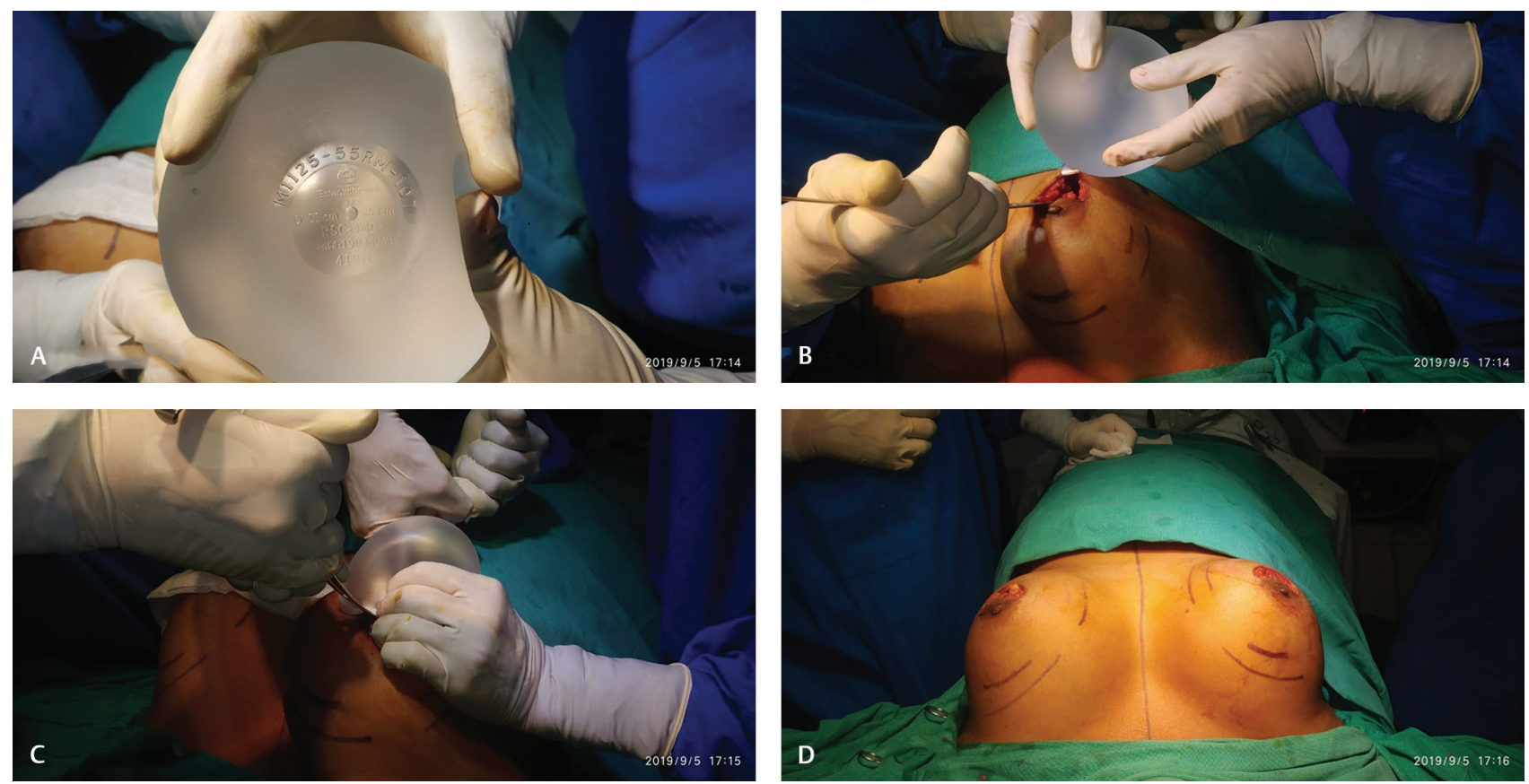

Fig. 7 Insertion of implant through periareolar incision. (A) $410 \mathrm{ml}$ implant. (B) The edges of ncision are retracted before beginning of insertion. (C) In the process of insertion. (D) Insertion completed.

movements for 3 weeks. Amoxycillin and clavulanic acid either $1.2 \mathrm{~g}$ twice daily or $625 \mathrm{mg}$ thrice daily (two authors follow different schedules) is prescribed for 10 days, analgesics and sedative are prescribed for 5 days. On the fifth day the dressings are changed and patient is asked to wear an inner brassiere and outer sports vest, antibiotic ointment like NEOSPORIN ${ }^{(R)}$ or fucidic acid are applied twice daily to the incision line for 7 days. If the wound is dry, bath is allowed in another two days.

Patients are taught massage of the breasts which is started 3 weeks after the operation in sequence of upward, downward, medial, and lateral firm pressure and circular motion with both hands in clockwise and anticlockwise manner for at least 20 minutes twice daily for a period of 6 weeks. In addition, patients are asked to lie prone for about two hours a day even if not at a stretch. Prior to 2014, routine closed capsulotomy maneuver used to be done at 3 weeks by one of the authors. Later, this was abandoned as it was found unnecessary if a proper massage regime is followed.

\section{Results and Analysis}

The increasing demand for breast augmentation in trans women is shown over the years in ( - Fig. 8). 


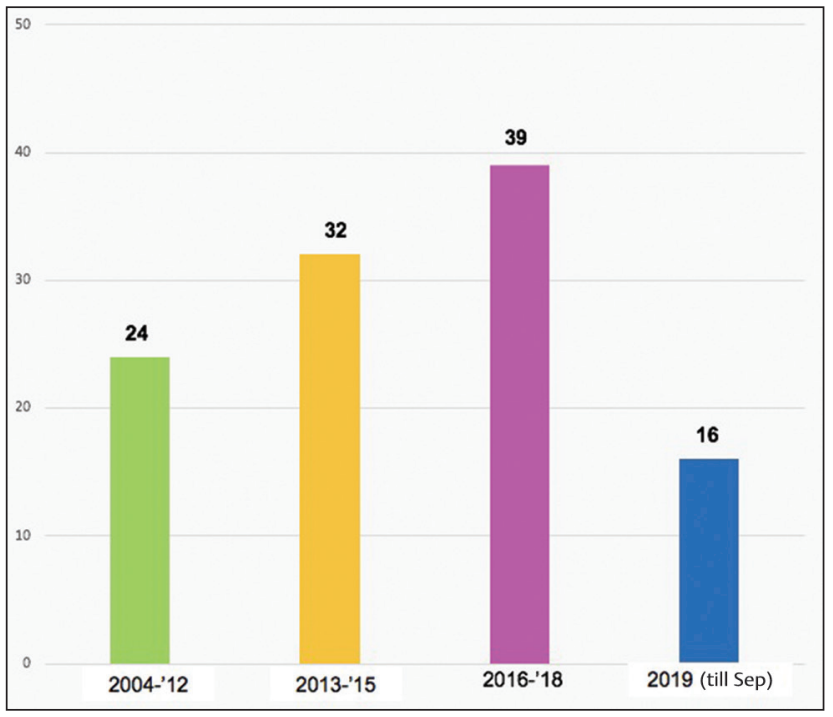

Fig. 8 Showing gradual increase in demands for breast augmentation over the years in our clinic. Between 2004 and 2012 the demand was 24; between 2013 and 2015 it was 32; between 2016 and 2018 it was 39; and in 2019 it was 16 (till September).

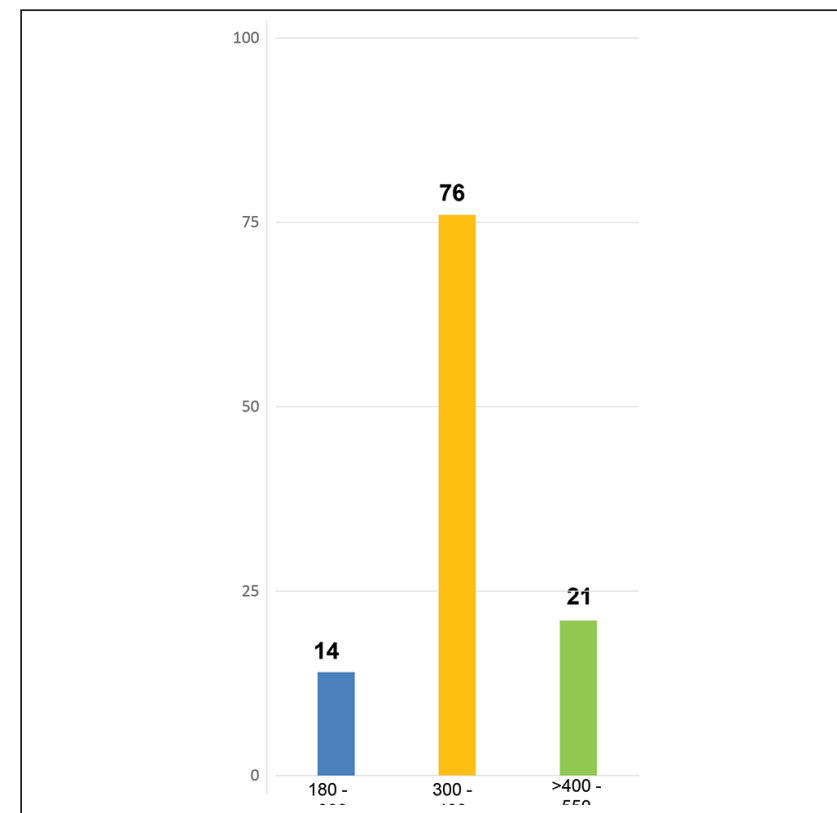

Fig. 9 Bar chart showing the size range of implants on $x$-axis and the number of implants on $y$-axis.
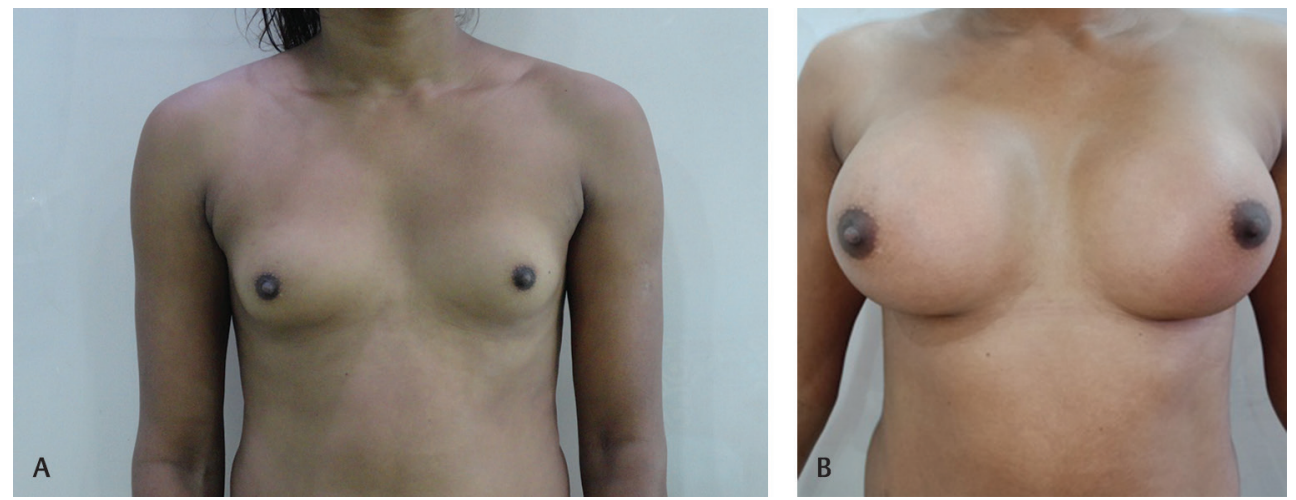

Fig. 10 (A) Preoperative picture. (B) Two months postoperative follow-up case of a $350 \mathrm{ml}$ smooth silicone gel implant via inframammary route.

Only cohesive silicone gel implants were used. Before 2017, 72 textured (Eurosilicone and Allergan) implants were used and later due to problems of availability, 39 smooth (Motiva) ones were inserted. We have not noted any difference in the available period of follow-up. The size of implants ranged from $180 \mathrm{~cm}^{3}$ to $550 \mathrm{~cm}^{3}$, with majority in the range of 300 to $400 \mathrm{~mL}$ ( - Fig. 9). Preoperative photographs and postoperative results with different sizes of implants and follow-up periods are presented in (-Figs. 10-16). Major complications like infection leading to ultimate extrusion occurred in one patient. It was later reported that the patient sustained trauma and possibly hematoma, leading to infection. Minor complications of delayed healing and minimal discharge from superficial part of the wound occurred in 18 cases of which 11 required secondary sutures. Rest healed conservatively. Seventeen of these occurred in periareolar incisions, only one in inframammary. Strong retraction is necessary at the edges of incision during insertion of the implant. The brunt of entire force of retraction falls on the subcutaneous fat. This might have been the cause of serous and oily discharge in some periareolar wounds. It must be remembered that only 4.5 to $5 \mathrm{~cm}$ of available crescent incision necessitated strong retraction of both edges during dissection of pocket and insertion of implants. Capsular contracture meriting operative intervention occurred only in two patients but one of them refused operation. Prominent veins have been noticed on surface in five patients, three of whom had very little subcutaneous tissue. Poor scarring was noticed in 11 patients needing secondary sutures. Intrakeloidal injection of triamcinolone was necessary in one patient.

Two patients in the series had their implants exchanged for a larger one ( $240 \mathrm{~mL}$ to $380 \mathrm{~mL}$ and $300 \mathrm{~mL}$ to $440 \mathrm{~mL}$ ) which were very smooth procedures with insertion in the same pocket without any other dissection or manipulation. 

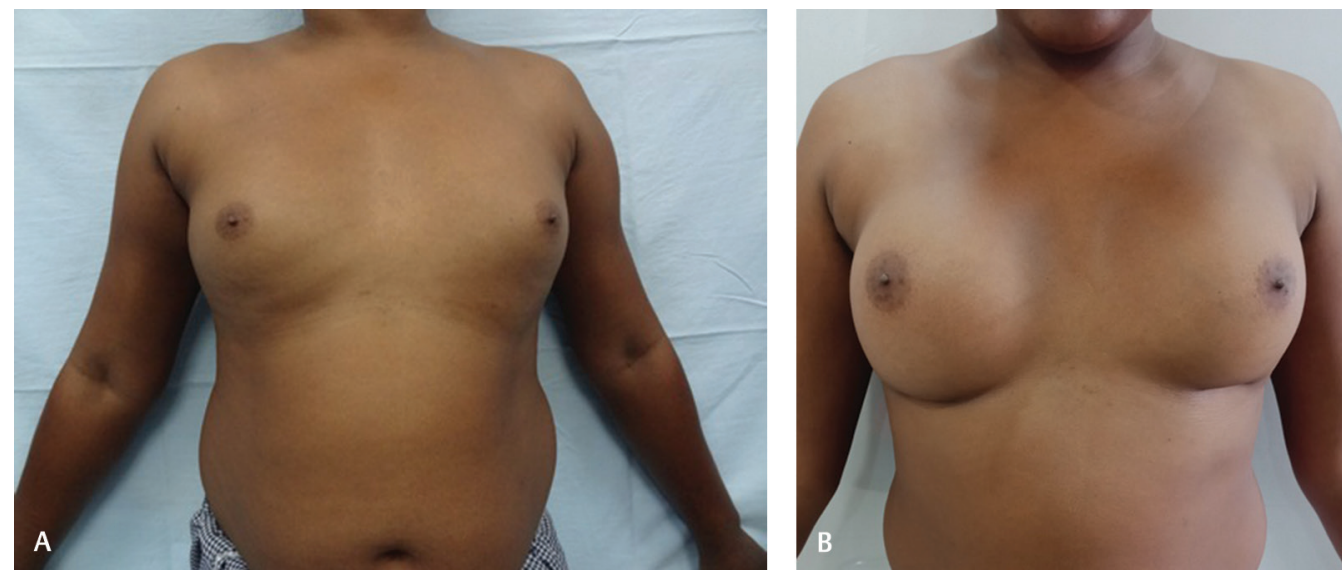

Fig. 11 (A) Preoperative picture. (B) Seven months postoperative follow-up of $380 \mathrm{ml}$ smooth implants via infra mammary route.
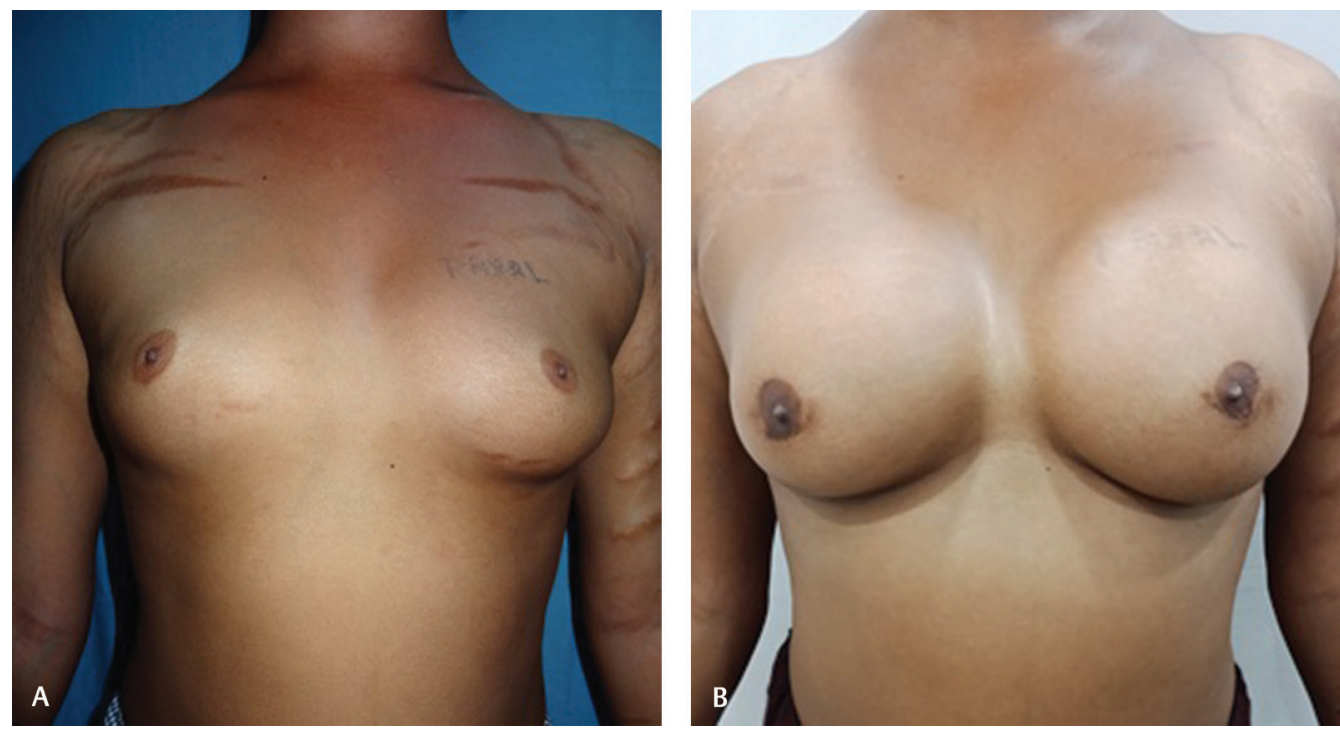

Fig. 12 (A) Preoperative picture. (B) 4 years 2 months follow-up of $300 \mathrm{ml}$ textured implants via periareolar route. Note the poor scarring due to delayed healing on the left side.
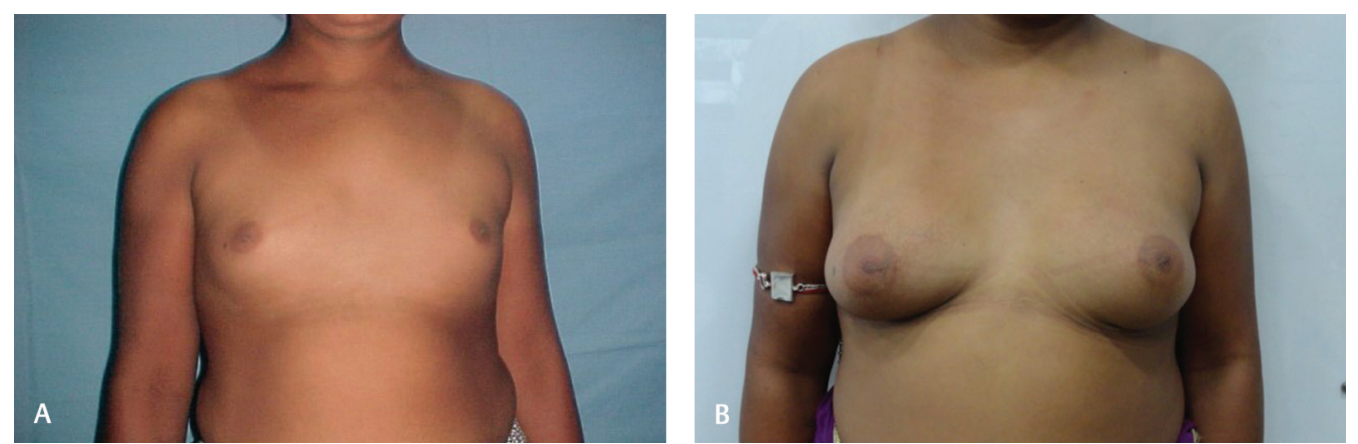

Fig. 13 (A) Preoperative picture. (B) 4 years 6 months follow-up of $340 \mathrm{ml}$ textured implant via inframammary route.

\section{Discussion}

Literature is sparse with regard to breast augmentation in trans women. The procedure differs from that of females in several ways because of the following reasons ${ }^{3,4}$ :

1. Broader shoulders.

2. Increased inter NAC distance and wider sternum.
3. Mostly small NACs.

4. Tight chest envelope.

5. Biologic women also have a shorter and more conical thorax with more fat in axilla and also at the insertion of muscles of the thorax, thus helping to smoothen and rounding of contours of the implant. Therefore, even a smaller implant gives a prominent cleavage with aesthetic results. 

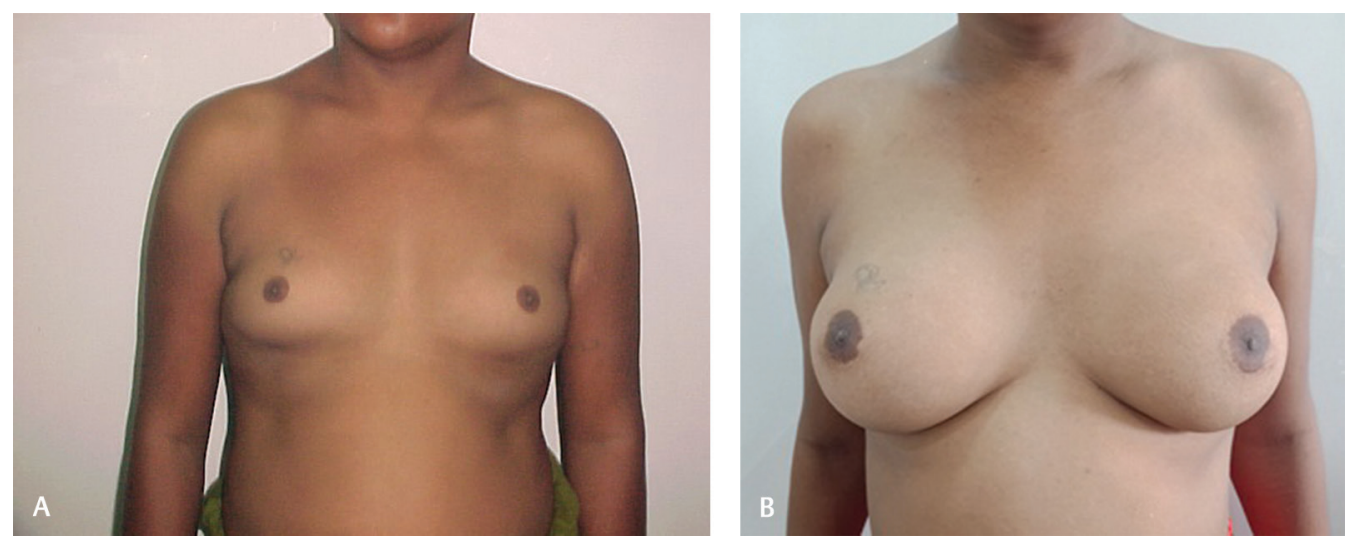

Fig. 14 (A) Preoperative picture. (B) 5 years 2 months follow-up of $410 \mathrm{ml}$ textured implant via periareolar route.
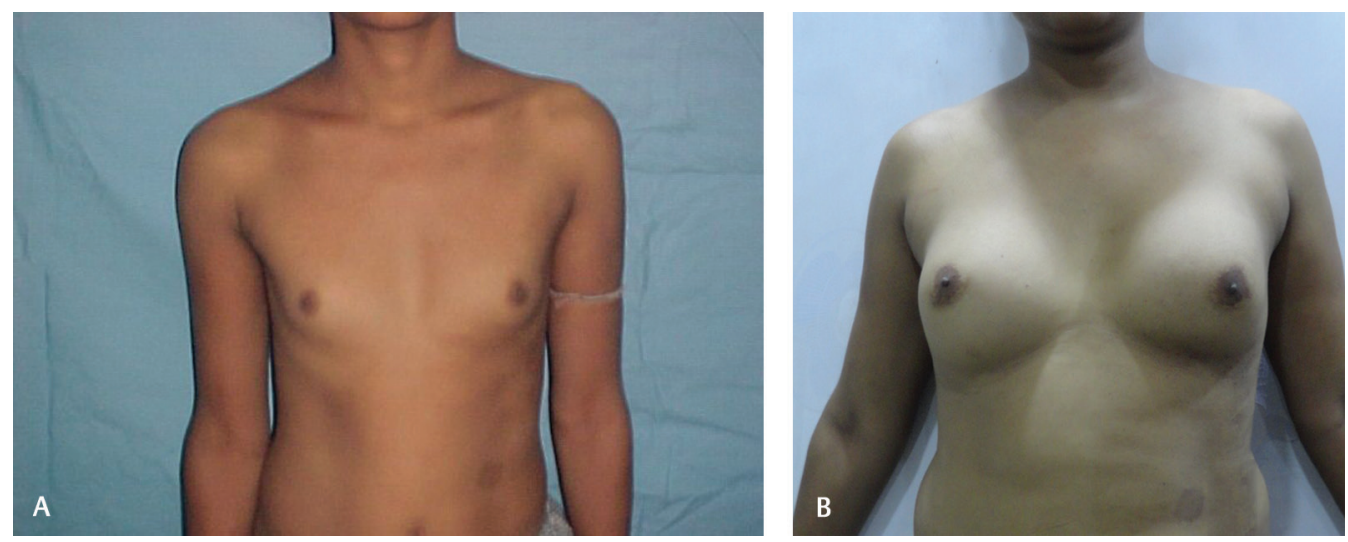

Fig. 15 (A) Preoperative picture. (B) 8 years follow-up of $240 \mathrm{ml}$ textured implant via periareolar route.

Nevertheless, their demand for large breasts and good cleavage is universal. When inter-NAC distance is large with a tight skin, this is impossible to achieve. A good cleavage requires a larger implant sufficiently spread over superomedial aspect. For an aesthetic appearance NAC should be central. The physical characteristics of the patient may not allow such a large implant which ensures both a good cleavage and centralization of NAC. But larger implants also cause the augmentation to look hemispherical and it is difficult to achieve natural ptosis. It is the authors' experience that trans women would prefer a cleavage to eccentricity of the implant even at a minor aesthetic cost similar to that reported in literature. ${ }^{1}$ Prior tissue expansion could help in such situation but this is invariably resented and the patients prefer subsequent larger implant exchange (-Fig. 16).

The common advice for breast implant is that if pinch test provides less than $2 \mathrm{~cm}$ of tissue in the pinch, the breast pocket should be submuscular. But trans women in our country mostly have an occupation requiring dancing postural movements and clapping. These demand a lot of chest muscle movement and possibility of animation of the implant in such situation is strongly resented.

Those who present after a reasonable period (about a year) of hormonal therapy do present with breast mound but the tightness is still evident and the mound consists mostly of fat offering poor resistance to suture bites in periareolar approach. Only a few with large breast mounds and dark NAC tend to have a better periareolar scar. Technically, however, dissection of pocket is easier by periareolar route than inframammary as it is more central. The tight skin envelope also demands strong retraction of proximal edge of the wound during dissection of the pocket ininframammary approach but healing is much faster as the breast mound is not disturbed.

Fixation of scarpa's fascia to deeper layer with at least three sutures to prevent implant malposition in female inframammary augmentation mammoplasty has been reported in literature. ${ }^{8}$ The difference with female breast augmentation is that in trans women, almost always a new inframammary line has to be created if such an incision is used. This is done by ensuring fixation of different layers of wound to its immediate deeper tissues to prevent upward migration of the scar and downward displacement of implant. Authors have no experience with transaxillary approach and would not like to venture as authors are not convinced of nature of cleanliness and hygiene of axilla, particularly with hot and humid conditions existing over 9 months a year.

Irrigation of the pocket with different antibiotic solutions with or without steroids ${ }^{9-11}$ and povidone iodine ${ }^{3,12}$ have been reported in literature for prevention of infection and capsular contracture. We had no problem with using povidone iodine $5 \%$ solution alone for past 18 years and would not like to switch over to any other regime. It is readily available and there is no need to prepare anything separately. Perhaps it is 

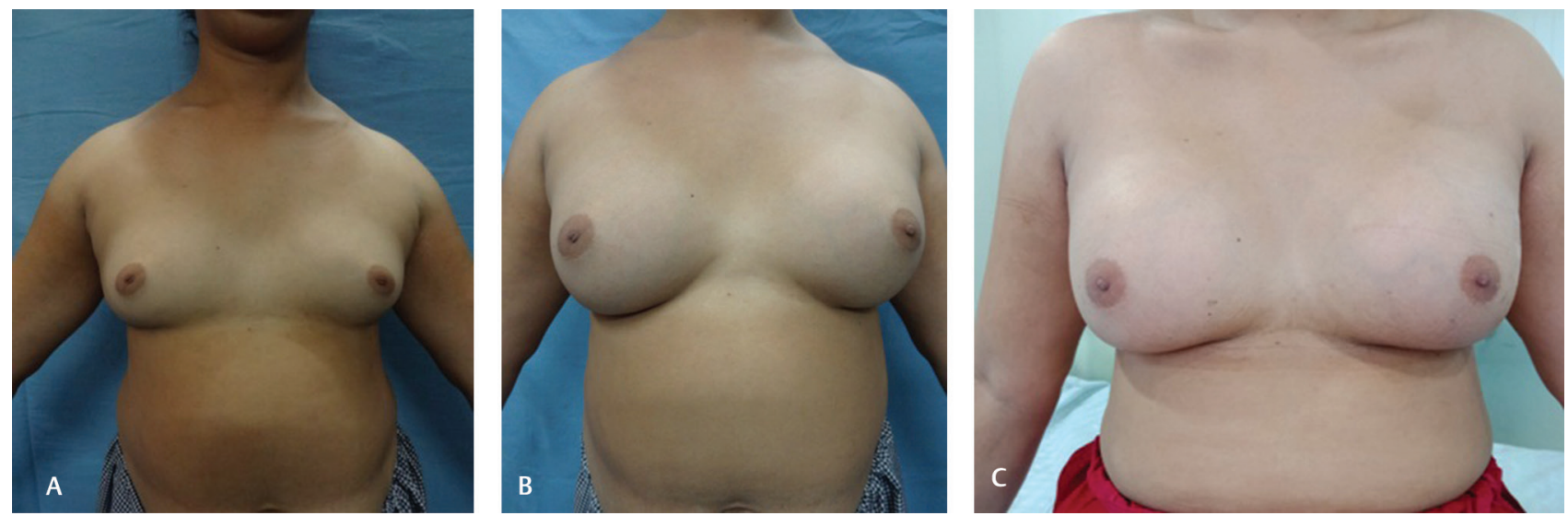

Fig. 16 (A) Preoperative before the first operation. (B) Result after 3 years 6 months of insertion of $300 \mathrm{~mL}$ of textured implant via inframmary route. (C) Result after 1 month of implant exchange from $300 \mathrm{~mL}$ textured to $440 \mathrm{ml}$ smooth implants via the previous incision.

more a matter of choice of surgeons rather than superiority of one regime over the other.

Capsular contracture ${ }^{13}$ which is said to be the commonest complication of breast implants in females has not bothered us to the same degree. It may be that this group of patients are not very aware of lower grades of contracture and do not mind a little firmness in the breast. Overall incidence of capsular contracture was around $11 \%$. Only two had grade IV contractures. One of them refused operation. It is also noticed that these patients do not like to use brassieres after breast augmentation and very few have ptosis, most likely due to tight skin envelope. However, those whose breast mounds are large do also suffer from ptosis as in biologic females.

\section{Conclusion}

Experience with 111 consecutive subfascial breast augmentation in trans women are presented. They are essentially men with castrated genitals. Operative details, protocols followed, postoperative recovery depending on route of insertion, and limitations proportionate to demands are all discussed. All implants were placed subfascially irrespective of tissue thickness in pinch test. These patients usually ignore capsular contracture unless it is grade IV. We have been able to limit contractures by proper massaging program. Inframammary route helps a much better recovery than periareolar route. It is noticed that a large size with a prominent cleavage is the wish of trans women even at the cost of a compromise in aesthetics.

\section{Conflict of Interest}

None.

\section{Acknowledgment}

The authors would like to acknowledge all the patients, members of the staff, particularly the operation theater staff attached to Enhance Clinic and Seba Niketan Nursing Home, Kolkata, particularly Ms. Sunita Dutta for their cooperation without which this article wouldn't see the light of the day.

\section{References}

1 Morrison SD, Wilson SC, Mosser SW. Breast and body contouring for transgender and gender nonconforming individuals. Clin Plast Surg 2018;45(3):333-342

2 Kanhai RC, Hage JJ, Mulder JW. Long-term outcome of augmentation mammaplasty in male-to-female transsexuals: a questionnaire survey of 107 patients. Br J Plast Surg 2000;53(3):209-211

3 Kanhai RC, Hage JJ, Karim RB, Mulder JW. Exceptional presenting conditions and outcome of augmentation mammaplasty in male-to-female transsexuals. Ann Plast Surg 1999;43(5):476-483

4 Laub DR, Fisk N. A rehabilitation program for gender dysphoria syndrome by surgical sex change. Plast Reconstr Surg 1974;53(4):388-403

5 Jinde L, Jianliang S, Xiaoping C, et al. Anatomy and clinical significance of pectoral fascia. Plast Reconstr Surg 2006;118(7):1557-1560

6 Graf RM, Bernardes A, Rippel R, Araujo LR, Damasio RC, Auersvald A. Subfascial breast implant: a new procedure. Plast Reconstr Surg 2003;111(2):904-908

7 Góes JC, Landecker A. Optimizing outcomes in breast augmentation: seven years of experience with the subfascial plane. Aesthetic Plast Surg 2003;27(3):178-184

8 Kim YJ, Kim YW, Cheon YW. Prevention of implant malposition in inframammary augmentation mammaplasty. Arch Plast Surg 2014;41(4):407-413

9 Adams WP Jr, Rios JL, Smith SJ. Enhancing patient outcomes in aesthetic and reconstructive breast surgery using triple antibiotic breast irrigation: six-year prospective clinical study. Plast Reconstr Surg 2006;117(1):30-36

10 Burkhardt BR, Dempsey PD, Schnur PL, Tofield JJ. Capsular contracture: a prospective study of the effect of local antibacterial agents. Plast Reconstr Surg 1986;77(6):919-932

11 Stevens WG, Nahabedian MY, Calobrace MB, et al. Risk factor analysis for capsular contracture: a 5-year Sientra study analysis using round, smooth, and textured implants for breast augmentation. Plast Reconstr Surg 2013;132(5):1115-1123

12 Yalanis GC, Liu EW, Cheng HT. Efficacy and safety of povidone iodine irrigation in reducing risk of capsular contracture in aesthetic breast augmentation: a systematic review and meta-analysis. Plast Reconstr Surg 2015;136(4):687-698

13 Spear SL, Baker JL Jr. Classification of capsular contracture after prosthetic breast reconstruction. Plast Reconstr Surg 1995;96(5):1119-1123, discussion 1124 